\title{
RELATIONS OF TOURIST PUSH AND PULL MOTIVATIONS WITH THEIR ACTIVITIES: THE CASE OF LITHUANIA
}

\author{
RASUOLE ANDRULIENE, AIDA MACERINSKIENE, \& SIGITAS URBONAVICIUS \\ Vilnius University, Lithuania.
}

\begin{abstract}
Tourist motivations are typically grouped into push and pull categories, and this classification is helpful for numerous analytical purposes. The objective of this study is to analyze how push and pull motivations are related with tourist activities in a destination country. Typically, pull motivations trigger tourist involvement in activities that are closely related with these motivations (like culture-related motivations with culture-related activities; nature-related motivation with nature-related activities, etc.). However, this is much less obvious in case of push motivations, since there are few activities that could be directly linked with the latter. The identified research gap needs to be explored. Possible tourist activities in a visited country are often rather typical; however, more specific preferences are influenced by the specifics of a destination, travel programme concepts and other characteristics of a particular trip. This makes the analysis of the relationship between motivations and activities relevant to broad contexts, but also allows one to include specifics of an analysed country. The study analyses a relation of push and pull motivations with tourist activities in Lithuania on the basis of a tourist survey that includes 374 respondents from 47 countries. The analysis is concentrated on linking four motivations (pull: nature-related and culture-related; push: escape and self-confidence increase) with three types of activities: culture-related activities, prestige-related activities and entertainment. Also, the age of tourists is used as an additional predictor in the regression analysis. The findings reveal that nature-related motivation has no significant relation with analyzed activities; culture-related motivations influence culture-related and prestige-related activities. Push motivations influence both prestige-related activities and entertainment. Age is a significant predictor for all the three activities; however, in case of entertainment the relation is negative. This adds to the current scope of scientific knowledge about predictors of the analysed types of tourist activities and has practical implications for the development of sustainable tourism.

Keywords: age, culture-related motivations, prestige-related motivations, pull motivations, push motivations, tourist activities.
\end{abstract}

\section{INTRODUCTION}

The scope of research on travelling includes a large amount of studies concentrating on tourist motivations [1-6]. Tourist motivations are analyzed from various perspectives and with various aims; therefore, studies provide extensive knowledge on relation of motivations with tourist demographics, culture, travel type, etc. On the other hand, tourist motivations are linked with characteristics of destinations and even tourists' expenditure during the trip [7-9]. So, there is extensive knowledge of the types of motivations regarding tourist segments, and knowledge of how motivations are linked with characteristics of the destination specifics. This is additionally supported by the common classification of tourist motivations into the categories of push-pull motivations [3, 10-19].

However, there is one more important aspect of tourist behaviour that deserves attention: this is the relation between the tourist motivations and activities they are engaged in in their destinations of visit. The research on this subject is yet scarce, and this study attempts to partially fill this gap in knowledge. The objective of this study is to specifically concentrate on analysis of the relation between push and pull motivations and tourist activities in a destination country. 
The issue of relating motivations with tourist activities carries both theoretical and practical importance. From the theoretical standpoint, the link between pull motivations and the corresponding activities is rather predictable. It is easy to expect a tourist, who is pulled by a specific attraction in a certain destination, to be engaged in activities that are offered by that attraction. However, the relation between push motivations and tourist activities is much less obvious. Therefore, additional insights on the issue might have a noticeable theoretical value.

From the practical point of view, a perfect match of tourist motivations and service offerings in tourist destinations is desirable, but not easily achievable without extensive analysis. Therefore, empirical evidence on the issue might also be valuable.

\section{LITERATURE AND HYPOTHESIS}

\subsection{Tourist activities and motivations}

While travelling, tourists are engaged in numerous activities that depend on a large set of factors; typically they are linked either with tourist characteristics or with their activities in a destination specifics [20,21]. Motivation can be referred to as psychological, biological needs and wants including the integral forces that arouse, direct and integrate a person's behaviour and activity $[6,10,13]$ or explained by heterogeneous nature of tourism motivation (multiple motivations) by proposing tourist typologies based on the relationship between personality and tourism activities undertaken [17]. So, both groups may be looked into through the prism of tourist motivations, analysed in this paper further on. However, tourist activities in the tourist destination are also linked with the resources/attractions available on the visited site [22].

The basic classification of tourism attractions includes natural resources, cultural and historical heritage, climate conditions, tourism infrastructure, tourist services and facilities [23]. However, this classification may be amended and detailed, addressing the specifics of a destination. Goeldner and Ritchie [24] suggested that natural attractions would typically include landscape, seascape, parks, mountains, flora, fauna, coasts, islands; cultural attractions refer to historical sites, architectural sites, architecture, cuisine, monuments, industrial sites, museums, theatre. Events (megaevents, community events, festivals, religious events, sport events, trade events) also present an important type of attractions that offer opportunities of participation; similarly, recreation (sightseeing, golf, swimming, tennis, hiking, biking, snow sports) and entertainment attractions (theme parks, amusement parks, casinos, shopping facilities, performing arts centres, sport complexes) offer relaxation and recreational activities.

Attraction is one of the most important components of the tourism product, directly linked with tourist destinations. Each destination offers a different variety of attractions and subsequent tourist activities, which creates a variety of choice opportunities for tourists when considering travel destinations [25].

Tourist activities are among the main issues that help to explain the link of tourist characteristics and motivations with the choice of tourist destinations [21]. Motivation has been referred to as psychological/biological/social needs and wants, including internal (or emotional) and external forces $[10,13]$. The motivation to travel refers to a set of needs that cause a person to participate in a tourism-based activity. In this sense, motivational factors are defined as the psychological needs that play a significant role in causing a person to feel psychological disequilibrium that may be corrected through a travel experience $[3,26]$. 
Analysis of tourist motivations can be based on various categorizations of motives. Goeldner and Ritchie [24] classified tourist motivations into: physical (relaxation); cultural (discovering new geographical areas); interpersonal (socializing and meeting new people) and prestige (related with self-esteem and self-actualization). Other categorizations emphasize different types of motivations (physical, emotional, personal, personal development, status and cultural) but there is an agreement that tourist activities vary depending on the type of their motivation $[14,27]$.

For instance, natural attractions often are the "mainsprings" that drive people to travel and be engaged in nature-related activities [8, 13, 24, 28]. Cultural attractions and activities are linked with culture-linked learning motivations, physical motivations encourage to visit destinations that offer relaxation and physical activities [12, 13, 15]. However, some other motivations (like escape motivation, emotional motivations, self-development motivations) do not have evident linkages with activities tourists might be interested in during travelling, and create difficulties for tourism developers. In this case, the classification of motivations into pull and push categories provides substantial benefits.

Numerous researchers agree that motivational forces fall into two large categories, one of them describing how individuals are pushed into making travel decisions internally while the second - how they are pulled or attracted by destination attributes [3, 10-13, 29].

\subsection{Pull motivations}

Essence of these motivations (they are strongly linked with the destination specifics, used in promotion to differentiate destinations, travel proposals, to link motivations with places and activities included into a travel programme).

Pull factors emerge as a result of the attractiveness of a destination [12, 22]. Pull motivations are those that are inspired by a destination's characteristics and attributes, such as accommodation, recreation facilities, cultural attractions, entertainment, natural scenery, shopping, and parks. The most typical pull factors include: nature [13, 15, 19]; heritage / culture / history / authentic experience [3,11, 13, 15, 31]; entertainment / outdoor sport activities [12, 13, 15]; city sightseeing and shopping [15, 30].

Among the pull motivations, an important place is taken by culture. It is one of the most significant drivers to decide about destinations [17]. Cultural tourism has recently become the fastest growing segment of the tourism industry, and this trend is evident in the rise of the volume of tourists who seek adventure, culture, history, archaeology and interaction with the local people [32].

It is logical to expect that the strongest relation exists between similar types of motivations and activities, such as culture-related motivation and culture-related activities, nature-related motivation and nature-related activities, etc. At the same time, it is hard to expect that pull motivations that are related with a corresponding type of activities would influence activities that correspond to another type of pull motivations. This allows to raise hypotheses:

H1: Culture-related motivation positively influences tourist involvement in culture-related activities;

H2: Nature-related motivation has no influence on tourist involvement in culture-related activities.

Pull motivations and destination attributes may stimulate and reinforce inherent push motivations $[11,13,31]$. 


\subsection{Push motivations}

Tourist motivations are not necessarily directly dependant on the characteristics of destinations. A group of push motivators is defined as origin-related factors and include intangible, intrinsic desires of a traveller such as a desire to escape, to have a rest and relaxation, adventure, health and prestige [12,27]. Again, various authors suggest their different categorizations, though the most typical categories are used in a large number of studies: escape from routine / escapism [3, 4, 11, 13, 19, 28, 29, 31, 33-35]; novelty and knowledge seeking [3, 11, 19, 33, 35-37]; ego enhancement / self-esteem / self-actualization [2, 3, 13, 19, 33, 36, 37]. Push motivations are internal / psychographic, rarely directly linked with specific activities in a destination; a person follows these motivations by engaging in activities that he/she personally considers the most relevant. Push factors are considered to be the socio-psychological needs of tourists and their environment that predispose the individual to travel or to participate in leisure activities, thus influencing travel decisions $[3,11,13,28,36]$. The set of activities that could be linked with push-related activities could be very broad, which are often linked with tourist personalities, demographics and to values that are typical to a culture of the country they represent. Push motivations only very indirectly 'predict' types of preferred activities. This study concentrates on two push motivations: self-esteem enhancement motivation and escape motivation.

The characteristics of self-esteem enhancement motivation and escape motivation allow to expect that tourists might prefer activities that have characteristics allowing to feel outside of their daily routine either by enjoying higher-level possibilities or just by being involved in relaxation. This study included two types of activities that supposedly could be linked with push motivations of tourists: prestige-related activities and entertainment. Therefore, the hypotheses are:

H3: Self-confidence increase motivation positively influences tourist involvement in prestige-related activities;

H4: Escape motivation positively influences tourist involvement in prestige-related activities;

H5: Self-confidence increase motivation positively influences tourist involvement in entertainment-related activities;

H6: Escape motivation positively influences tourist involvement in entertainment-related activities.

\subsection{Age}

Age is one of the most important demographic variables of tourists. It influences or even predetermines the range of preferred activities, and has specific links with certain types of motivations.

First of all, a younger age might be linked with better physical conditions of a tourist and, therefore, predetermine a broader spectrum of activities that require physical strength. Also, a younger age is often linked with higher levels of novelty-seeking and lower risk aversion. Therefore, it may be expected that younger tourists would prefer more active and challenging attractions.

On the other end, senior travellers have significantly longer life experience, clearer priorities in terms of interests and are interested in different aspects of learning. Combined with higher financial possibilities, this might trigger interest in cultural and learning-related activities, supported with adequate levels of safety and status / prestige. It is assumed that age 
influences all the three activities included into the current study. However, based on the findings of former studies, it is assumed that age has positive relation with culture-related activities and prestige-related activities, but negative with active entertainment.

H7: Age positively influences tourist involvement in culture-related activities;

H8: Age positively influences tourist involvement in prestige-related activities;

H9: Age positively influences tourist involvement in entertainment-related activities.

\section{SURVEY INSTRUMENT AND DATA}

The study is based on the data collected in Lithuania, surveying tourists-visitors of Vilnius Tourist Information Centre. Tourists were invited to participate in the survey, administrated by employees of the Centre. The questionnaire for this study had two essential parts: measurement of tourist motivations (the major set of independent variables) and measurement of their involvement in various activities during the current trip (dependent variables). In order to achieve consistency, both sets of statements have been developed by largely following the same study [8]. However, the list of statements was modified on the basis of 4 interviews with experts that are directly working with tourists in Lithuania. This allowed to modify / amend the list of statements with consideration of motivations that tourists declared in surveys/ interviews while surveyed in Lithuania as well as with the specifics of activities offered to tourists in the country. Based on expert recommendations, the list of motivation statements has been amended with motivations that reflect local specifics (like: 'to try traditional food', 'to understand Lithuanian style of living'). The total set of 21 statements included both pull and push motivations. The finalized list of activities included 15 items that are specific to the country.

Additionally, the survey included demographic questions about respondent age, measured in 8 groups (under 15, 15-19, 20-24, 25-34, 35-44, 45-54, 55-64, 65+) and the information regarding the country a tourist is from.

The total of 374 respondents have been surveyed; the sample included respondents from 47 countries. No country dominated the sample; the largest number of respondents were from Germany (13.9\% of the total), followed by United Kingdom (7.2\%), Sweden (6.7\%), the USA (6.7\%), France (6.4\%), Norway (6.1\%), Poland (5.6\%), Spain $(5.3 \%)$ and Russia $(5.1 \%)$, respondents from all other countries making up $37.0 \%$. This allowed to receive a sample that fairly well represents a large number of countries.

Distribution by age has been recorded in 8 age groups: under $15(0.3 \%), 15-19(1.3 \%)$, 20-24 (9.6\%), 25-34 (24.1\%), 35-44 (18.2\%), 45-54 (21.7\%), 55-64 (19.0\%), 65+ (5.9\%). This breakdown was satisfactory for the use in further analysis.

No unengaged respondents have been detected during the initial screening of the obtained data. 147 instances of missing data have been replaced by series means; this is less than $1.2 \%$ and is appropriate for such type studies. Variable screening allowed to identify 3 instances of skewness that exceeds 2 (which is within an appropriate range), and 10 instances of kurtosis above 3. Generally, this is reasonable due to the specifics of questions in the study, special attention was given to further process these variables.

\section{ANALYSIS}

\subsection{Factor analysis and reliability}

The analysis has been performed using SPSS 23 software, performing exploratory factor analysis and subsequent testing of hypotheses on the basis of correlation analysis. 
The aim of the exploratory factor analysis was to define factors that allow to measure planned motivations (pull: nature-related and culture-related; push: escape and selfconfidence increase) and activities (culture-related activities, prestige-related activities and entertainment-related activities). Extraction method of maximum likelihood and Promax rotation with Kaiser Normalization have been applied.

Exploratory factor analysis of motivations allowed to extract the three planned variables: nature-related and culture-related and self-confidence increase. KMO and Bartlett's test high significance $(\mathrm{p}=0.000)$, Kaiser-Meyer-Olkin measure of sampling adequacy $=0.737$; approx. chi-square $=828.634 ; \mathrm{df}=66$. There was $1(1.0 \%)$ non-redundant residual with absolute value greater than 0.05 . Together, the three considered factors explain 36.66 of the variance (Table 1).

The escape motivation has been measured by a single item ('to get away from everyday life'), and is further used in the regression analysis as a single-item variable.

Exploratory factor analysis of activities allowed to extract two planned variables: naturerelated and culture-related and self-confidence increase. KMO and Bartlett's test high significance $(\mathrm{p}=0.000)$, Kaiser-Meyer-Olkin measure of sampling adequacy $=0.663$; approx. chi-square $=460.446 ; \mathrm{df}=28$. There was $1(3.0 \%)$ non-redundant residual with absolute value greater than 0.05 . Together, the three considered factors explain $34.11 \%$ of the variance (Table 2).

\subsection{Testing hypothesis}

The hypotheses are tested on the basis of three multiple regression models that use the same set of predictors (four motivations and age) and three different dependent variables: culturerelated activities, prestige-related activities and entertainment-related activities. This allows

Table 1: Motivation Factors.

\begin{tabular}{llll}
\hline & Factor 1 & Factor 2 & Factor 3 \\
\cline { 2 - 4 } & $\begin{array}{l}\text { Nature-related } \\
\text { motivations }\end{array}$ & $\begin{array}{l}\text { Culture-related } \\
\text { motivations }\end{array}$ & $\begin{array}{l}\text { Self-confidence } \\
\text { increase } \\
\text { motivations }\end{array}$ \\
\hline Travel motivation items & & 0.579 & \\
To participate in cultural events & & 0.969 & \\
$\begin{array}{l}\text { To be close to nature } \\
\text { To visit nature attractions }\end{array}$ & 0.724 & & \\
$\begin{array}{l}\text { To engage in nature-based activities } \\
\text { To have experiences to talk about }\end{array}$ & 0.599 & & 0.402 \\
To improve your self-confidence & & & 0.649 \\
To obtain a feeling of achievement & & 12.552 & 0.643 \\
$\begin{array}{l}\text { Eigenvalue } \\
\text { \% of variance explained }\end{array}$ & 26.235 & 10.82 & 6.52 \\
Cronbach's alpha & 15.32 & 0.665 & 0.614 \\
\hline
\end{tabular}


Table 2: Activities Factors.

\begin{tabular}{lll}
\hline & Factor 1 & Factor 2 \\
\cline { 2 - 3 } Tourist activities items & $\begin{array}{l}\text { Culture-related } \\
\text { activities }\end{array}$ & $\begin{array}{l}\text { Prestige-related } \\
\text { activities }\end{array}$ \\
\hline Visiting museums/galleries & 0.500 & \\
Appreciating architecture & 0.937 & \\
Visiting historic places & 0.536 & 0.677 \\
Visiting high quality restaurants & & 0.685 \\
Staying in first class accommodation & & 0.441 \\
Shopping & & 18.454 \\
Eigenvalue & 28.976 & 13.26 \\
\% of variance explained & 20.85 & 0.617 \\
Cronbach's alpha & 0.670 & \\
\hline
\end{tabular}

to test the hypotheses and provide broader interpretations of the relations between predictors and the three activities. ANOVA was used to check variances between the main variables.

The first linear regression model (independent variables: age culture-related motivation, nature-related motivation, self-confidence increase motivation, escape motivation; dependent variable culture-related activities) showed $\mathrm{F}=16.950$ and $\mathrm{p}=0.000$ for ANOVA, adjusted $\mathrm{R}^{2}=0.177$. The whole model is presented in Table 3 .

The model allows to test three hypotheses: H1, H2, H7.

Culture-related motivation has significant $(\mathrm{p}=0.000)$ and relatively strong $(\beta=0.252)$ positive relation with culture-related activities. This type of motivation can be interpreted to positively influence tourist involvement in culture-related activities (the way it was predicted) since there is a direct match between the pull type of motivations and the type of activities. Therefore $\mathrm{H} 1$ is confirmed.

Table 3: Regression model 1 (dependent variable - tourist involvement in culture-related activities).

\begin{tabular}{|c|c|c|c|c|c|}
\hline \multirow[b]{2}{*}{ Model } & \multicolumn{2}{|c|}{$\begin{array}{l}\text { Unstandardized } \\
\text { coefficients }\end{array}$} & \multicolumn{2}{|c|}{$\begin{array}{l}\text { Standardized } \\
\text { coefficients }\end{array}$} & \multirow[b]{2}{*}{ Sig. } \\
\hline & $\mathrm{B}$ & Std. Error & Beta & $\mathrm{t}$ & \\
\hline (Constant) & -0.773 & 0.298 & & -2.596 & 0.010 \\
\hline Age & 0.140 & 0.030 & 0.226 & 4.687 & 0.000 \\
\hline Nature-related motivation & 0.002 & 0.071 & 0.002 & 0.032 & 0.975 \\
\hline Culture-related motivation & 0.234 & 0.052 & 0.252 & 4.523 & 0.000 \\
\hline $\begin{array}{l}\text { Self-confidence increase } \\
\text { motivation }\end{array}$ & 0.142 & 0.075 & 0.126 & 1.899 & 0.058 \\
\hline Escape motivation & 0.007 & 0.059 & 0.006 & 0.113 & 0.910 \\
\hline
\end{tabular}


$\mathrm{H} 2$ predicted that relation between nature-related motivations and culture-related activities does not exist, since this pull motivation does not match the type of the activities. The model confirms this prediction, since the relation between these variables is not significant ( $\mathrm{p}=0.975)$. This allows to confirm $\mathrm{H} 2$.

The model allows to test the influence of age on tourist involvement in culture-related activities. This influence is significant $(\mathrm{p}=0.000)$ and positive $(\beta=0.226)$. Therefore, $\mathrm{H} 7 \mathrm{is}$ confirmed.

Additionally, the model allows to see that none of the push motivations that are considered in this study significantly predicts tourist involvement in culture-related activities at the level of significance 0.05 ; however, self-confidence increase motivation could be considered among the predictors at level of 0.1 .

The second linear regression model with the same independent variables and the dependent variable prestige-related activities showed $\mathrm{F}=16.447$ and $\mathrm{p}=0.000$ for ANOVA, adjusted $\mathrm{R}^{2}=0.172$. The model is in Table 4 .

This model allows to test hypotheses: H3, H4, H8.

Self-confidence increase motivation has significant $(\mathrm{p}=0.018)$ positive $(\beta=0.159)$ influence on prestige-related activities. Similarly, escape motivation also has significant $(\mathrm{p}=0.011)$ and positive $(\beta=0.125)$ influence on the same type of activities. This allows to confirm both $\mathrm{H} 3$ and $\mathrm{H} 4$ and see that prestige-related activities are influenced by push motivations. However, the analysis shows that this type of activities is also influenced by culture-related (pull) motivations, which has not been hypothesized. This relation requires additional discussion and interpretation.

The model allows to test $\mathrm{H} 8$ regarding the influence of age on tourist involvement in prestige-related activities. The influence is significant $(\mathrm{p}=0.020)$ and positive $(\beta=0.113)$; the hypothesis is confirmed.

The third regression model analyses the influence of the same predictors on tourist involvement in entertainment-related activities. Model fit is good, $\mathrm{F}=26.956$ and $\mathrm{p}=0.000$ for ANOVA, adjusted $\mathrm{R}^{2}=0.263$. Table 5 shows this model in detail.

The model tests hypotheses H5, H6, H9.

Again, it has been hypothesized that the two analyzed push motivations (self-confidence increase and escape) similarly and positively influence tourist involvement in activities that

Table 4: Regression model 2 (dependent variable - tourist involvement in prestige-related activities).

\begin{tabular}{llllll}
\hline & \multicolumn{2}{l}{$\begin{array}{l}\text { Unstandardized } \\
\text { coefficients }\end{array}$} & \multicolumn{2}{l}{$\begin{array}{l}\text { Standardized } \\
\text { coefficients }\end{array}$} & \\
\cline { 2 - 5 } Model & $\mathrm{B}$ & Std. Error & Beta & $\mathrm{t}$ & Sig. \\
\hline (Constant) & -0.915 & 0.268 & & -3.414 & 0.001 \\
Age & 0.063 & 0.027 & 0.113 & 2.333 & 0.020 \\
Nature-related motivation & 0.081 & 0.064 & 0.086 & 1.266 & 0.206 \\
Culture-related motivation & 0.155 & 0.047 & 0.186 & 3.324 & 0.001 \\
$\begin{array}{l}\text { Self-confidence increase } \\
\text { motivation }\end{array}$ & 0.160 & 0.067 & 0.159 & 2.380 & 0.018 \\
Escape motivation & 0.135 & 0.053 & 0.125 & 2.555 & 0.011 \\
\hline
\end{tabular}


Table 5: Regression model 3 (dependent variable - tourist involvement in entertainmentrelated activities).

\begin{tabular}{lcclrl}
\hline & \multicolumn{2}{l}{$\begin{array}{l}\text { Unstandardized coeffi- } \\
\text { cients }\end{array}$} & \multicolumn{2}{l}{$\begin{array}{l}\text { Standardized } \\
\text { coefficients }\end{array}$} & \\
\cline { 2 - 5 } Model & $\mathrm{B}$ & Std. Error & Beta & $\mathrm{t}$ & Sig. \\
\hline (Constant) & 4.007 & 0.387 & & 10.360 & 0.000 \\
Age & -0.422 & 0.038 & -0.508 & -11.038 & 0.000 \\
Nature-related motivation & -0.043 & 0.091 & -0.031 & -0.475 & 0.635 \\
Culture-related motivation & 0.067 & 0.066 & 0.054 & 1.021 & 0.308 \\
Self-confidence increase mo- & 0.214 & 0.096 & 0.142 & 2.229 & 0.026 \\
tivation & & & & & \\
Escape motivation & 0.166 & 0.077 & 0.102 & 2.159 & 0.032 \\
\hline
\end{tabular}

provide relaxation and entertainment. Analysis shows that the assumptions are correct: both push motivations have significant $(\mathrm{p}=0.026$ and $\mathrm{p}=0.032)$ and positive $(\beta=0.142$ and $\beta=0.102$ ) influence on entertainment-related activities. Therefore H5 and H6 are confirmed.

At the same time, this type of activities is not influenced by the two pull motivations considered in the model, but strongly negatively influenced by tourist age $(p=0.000)$, ( $\beta=-0.508)$. This allows to confirm hypothesis $\mathrm{H} 9$.

\section{CONCLUSIONS, LIMITATIONS AND FURTHER RESEARCH}

The objective of this study was to analyse of the relation between push and pull motivations and tourist activities in a destination country. Though the study was of exploratory content, it allows drawing certain conclusions.

The most general conclusion of the current study is the evidence that the relation between various types of tourist motivations is significant and may be analyzed. The analysis provides substantial knowledge of the relations between the specific motivations and activities, and further targeted studies of this type may have very clear managerial implications regarding the tourist segmentations and development of tourist services appealing to the defined segments.

More specifically, the study disclosed that pull motivations trigger only the activities that directly correspond to the type of their pull motivations, and there is little expectation that activities that are linked with another type of pull motivations would appeal to tourists who visit the site driven by another pull motivator. This means that the main promotional efforts have to be directed towards potential tourists before the trip, while additional offering of a different type attractions during the visit period might have little value.

The analysed push motivations showed their relations with activities that offer relaxation of various types, including entertainment and activities that include luxury, high quality and shopping (prestige-related activities). Somehow surprisingly, prestige-related activities were also influenced by culture-related motivations. Therefore, visiting upper-scale places and doing shopping in a different country might be said to at least partially involve exploration of a different culture. 
Finally, age was an important predictor of all the three analysed activities. As expected, its influence was negative in case of active entertainment activities.

This study has obvious limitations.

The attempt was made to explore a large number of motivations and tourist activities with little concentration of the destination specifics. This resulted in difficulties in factor analysis and measurements of planned variables. In future studies the specificity of destinations requires much more attention.

The scope of the study included tourists from a large number of countries. This represented a variety of tourists fairly well, however, simultaneously limiting opportunities to perform a deeper analysis by the countries the tourists are from: the number of tourists per country was not sufficient for that. An enlarged number of respondents per country would allow to observe specificities on the country basis, since both motivations and activities may dependent on the cultural contexts tourists come from.

Finally, seeing the importance of age, future studies should include a larger number of demographic indicators in order to better predict preferred activities of the tourists.

\section{REFERENCES}

[1] Cohen, E., Toward sociology of international tourism. Social Research, 39(1), pp. 164 182, 1972.

[2] Dann, G.M.S., Anomie, ego-enhancement and tourism. Annals of Tourism Research, 4, pp. 184-194, 1977. https://doi.org/10.1016/0160-7383(77)90037-8

[3] Crompton, J.L., Who is a tourist? a conceptual clarification. Sociological Review, 22, pp. 527-555, 1979.

https://doi.org/10.1111/j.1467-954x.1974.tb00507.x

[4] Klenosky, D., The "Pull" of tourism destinations: a means-end investigation. Journal of Travel Research, 40(4), pp. 385-395, 2002. https://doi.org/10.1177/0047287502040004005

[5] Gnoth, J., Tourism motivation and expectation formation. Annals of Tourism Research, 24(2), pp. 283-304, 1997. https://doi.org/10.1016/s0160-7383(97)80002-3

[6] Pearce, P.L., Perceived changes in holiday destinations. Annals of Tourism Research, 9(2), pp. 145-164, 1982. https://doi.org/10.1016/0160-7383(82)90044-5

[7] Legohérel, P. \& Wong, K.K.F., Market segmentation in the tourism industry and consumers spending: what about direct expenditures? Journal of Travel and Tourism Marketing, 20(2), pp. 15-30, 2006. https://doi.org/10.1300/j073v20n02_02

[8] Mehmetoglu, M., Typologising nature-based tourists by activity - Theoretical and practical implications. Tourism Management, 28, pp. 651-660, 2007. https://doi.org/10.1016/j.tourman.2006.02.006

[9] Jang, S. \& Ham, S., A double-hurdle analysis of travel expenditure: baby boomers seniors versus older seniors. Tourism Management, 30, pp. 372-380, 2009. https://doi.org/10.1016/j.tourman.2008.08.005

[10] Dann, G.M.S., Tourist motivation: an appraisal. Annals of Tourism Research, 8, pp. 187-219, 1981. https://doi.org/10.1016/0160-7383(81)90082-7 
[11] Yuan, S. \& McDonald, C., Motivational determinants of international pleasure time. Journal of Travel Research, 24(1), pp. 42-44, 1990.

https://doi.org/10.1177/004728759002900109

[12] Uysal, M. \& Jurowski, C., Testing the push and pull factors. Annals of Tourism Research, 21(4), pp. 844-846, 1994.

https://doi.org/10.1016/0160-7383(94)90091-4

[13] Uysal, M. \& Hagan, L.A.R., Motivations of Pleasure Travel and Tourism. Encyclopedia of Hospitality and Tourism, eds. M. Khan, M. Olsen T. Var, New York: Van Nostrand Reinhold, pp. 798-810, 1993.

[14] Jang, S. \& Cai, L.A., Travel motivations and destination choice: a study of British outbound market. Journal of Travel and Tourism Marketing, 13(3), pp. 111-133, 2002. https://doi.org/10.1080/10548400209511570

[15] You, X., O’Leary, J., Morrison, A. \& Hong, G., A cross-cultural comparison of travel push and pull factors: United Kingdom vs. Japan. International Journal of Hospitality and Tourism Administration, 1(2), pp. 1-26, 2000. https://doi.org/10.1300/j149v01n02_01

[16] Baloglu, S. \& Uysal, M., Market segments of push and pull motivations: a canonical correlation approach. International Journal of Contemporary Hospitality Management, 8, pp. 32-38, 1996. https://doi.org/10.1108/09596119610115989

[17] Kozak, M., Comparative analysis of tourist motivations by nationality and destinations. Tourism Management, 23(3), pp. 221-232, 2002. https://doi.org/10.1016/s0261-5177(01)00090-5

[18] Yoon, Y. \& Uysal, M., An examination of the effects of motivation and satisfaction on destination loyalty: a structural model. Tourism Management, 26, pp. 45-56, 2005. https://doi.org/10.1016/j.tourman.2003.08.016

[19] Lee, G., O'Leary, J., Lee, S. \& Morrison, A. Comparison and contrast of push and pull motivational effects on trip behavior: an application of a multinational logistic regression model. Tourism Analysis, 7, pp. 89-104, 2002. https://doi.org/10.3727/108354202108749970

[20] Hsieh, S., O`Leary, J.T. \& Morrison, A.M., Segmenting the international travel market by activity. Tourism Management, 13, pp. 209-223, 1992.

https://doi.org/10.1016/0261-5177(92)90062-c

[21] Moscardo, G., Morrison, A.M., Pearce, P.L., Lang, C. \& O’Leary, J.T., Understanding vacation destination choice through travel motivation and activities. Journal of Vacation Marketing, 2, pp. 109-122, 1996. https://doi.org/10.1177/135676679600200202

[22] Formica, S. \& Uysal, M., Destination attractiveness based on supply and demand evaluations: an analytical framework. Journal of Travel Research, 44, pp. 418-430, 2006. https://doi.org/10.1177/0047287506286714

[23] McIntyre, G., Hetherington, A. \& Inskeep, E., Sustainable Tourism Development: Guide for Local Planners. Madrid: UNWTO, 1993.

[24] Goeldner, C.R. \& Ritchie, J.R.B., Tourism: Principles, Practices, Philosophies, 11thed. New York, NY: John Wiley \& Sons, Inc., 2009.

[25] Crompton, J.L., Structure of vacation destination choice sets. Annals of Tourism Research, 19, pp. 420-434, 1992. https://doi.org/10.1016/0160-7383(92)90128-c 
[26] Kim, S.S., Botha, C. \& Crompton, J.L., Responding to competition: a strategy for Sun/ Lost City, South Africa. Tourism Management, 21(1), pp. 33-42, 2000.

https://doi.org/10.1016/s0261-5177(99)00094-1

[27] Horner, S. \& Swarbrooke, J., Consumer Behaviour in Tourism - 2nd ed., Oxford: Butterworth Heinemann, 2007.

[28] Kim, S.S. \& Lee, C.K., Push and pull relationships. Annals of Tourism Research, 29(1), pp. 257-260, 2002. https://doi.org/10.1016/s0160-7383(01)00043-3

[29] Pearce, P., Marketing and management trends in tourist attractions. Asia Pacific Journal of Tourism Research, 3(1), pp. 1-8, 1998. https://doi.org/10.1080/10941669908722002

[30] Sirakaya, E., McLellan, R.W. \& Uysal, M., Modeling vacation destination decisions: a behavioral approach. Journal of Travel and Tourism Marketing, 5, pp. 57-75, 1996. https://doi.org/10.1300/j073v05n01_05

[31] Iso-Ahola, S.E., Towards a social psychology of tourist motivation: a rejoinder. Annals of Tourism Research, 9, pp. 256-261, 1982. https://doi.org/10.1016/0160-7383(82)90049-4

[32] Hughes, H. \& Allen, D., Cultural tourism in Central and Eastern Europe: the views of 'induced image formation agents'. Tourism Management, 26, pp. 173-183, 2005. https://doi.org/10.1016/j.tourman.2003.08.021

[33] Jang, S., Morrison, A. \& O'Leary, J., A procedure for target market selection in tourism. Journal of Travel and Tourism Marketing, 16(1), pp. 17-31, 2004. https://doi.org/10.1300/j073v16n01_03

[34] Kim, S.S., Lee, C. \& Klenosky, D., The influence of push and pull factors at Korean National Parks. Tourism Management, 24(2), pp. 169-180, 2003. https://doi.org/10.1016/s0261-5177(02)00059-6

[35] Li, M., Zhang, H. \& Cai, A.L., A subcultural analysis of tourism motivations. Journal of Hospitality and Tourism Research, 40(1), pp. 85-113, 2016. https://doi.org/10.1177/1096348013491601

[36] Fodness, D., Measuring tourist motivation. Annals of Tourism Research, 21(3), pp. 555558, 1994. https://doi.org/10.1016/0160-7383(94)90120-1

[37] Sangpikul, A., A factor-cluster analysis of tourist motivations: a case of U.S. Senior travelers. Tourism, 56(1), pp. 23-40, 2008.

[38] Uysal, M., Li, X. \& Sirakaya-Turk, E., Push-pull dynamics in travel decisions. Handbook of Hospitality Marketing Management, pp. 412-437, 2008. 